\title{
Arqueología de puertas adentro: La cerámica de El Garcel (Antas, Almería) Indoor archaeology: El Garcel's pottery (Antas, Almería)
}

Ruth Maicas Ramos ${ }^{1}$

María de la Paz Román Díaz ${ }^{2}$

\section{Resumen}

El Museo Arqueológico Nacional (MAN) conserva la mejor colección de materiales y documentos reunidos por los hermanos Siret en el Sudeste peninsular. Nos centraremos aquí en el estudio de los materiales cerámicos de uno de los más polémicos yacimientos de esta colección: El Garcel. A través de este conjunto de materiales se plantean propuestas sobre sus funciones principales a partir de su caracterización y la información etnoarqueológica.

Palabras clave: Cerámica, Neolítico, Calcolítico, Edad del Bronce, Sureste peninsular.

\begin{abstract}
The Museo Arqueológico Nacional (MAN) preserves the best collection on materials and documents formed by the Siret brothers in the Southest of Spain. The pottery assemblage recovered on the controversial site of El Garcel has been described in this paper. Through this set of materials, a proposal on their main functions based on characterization and ethnoarchaeological data has been suggested.
\end{abstract}

Keywords: Pottery, Neolithic, Chalcolithic, Bronze Age, Southeast Iberian peninsula.

\section{INTRODUCCIÓN}

El registro arqueológico que llega hasta nosotros es una pequeña parte de lo que en su momento fue la vida de nuestros antepasados, pero cuando nos enfrentamos al estudio de colecciones antiguas, lo hacemos además a otros tipos de pérdidas de información determinadas por la propia historia que los materiales excavados han sufrido desde el momento de su recuperación.

Pese a ello, defendemos el estudio de estas colecciones al corresponder a conjuntos emblemáticos y proceder de áreas arrasadas, lo que las convierte en la única fuente de aproximación a su pasado.

Nos ocuparemos aquí de un subconjunto de la colección Siret del Museo Arqueológico Nacional (MAN) que corresponde a los materiales cerámicos de El Garcel (Antas, Almería). Aunque este yacimiento ha sido mencionado numerosas veces en la literatura arqueológica, lo cierto es que no es tan amplio el conocimiento directo de sus materiales. Nos gustaría dedicar este trabajo a la Dra. Isabel Rubio con quien compartimos el interés por

Departamento de Prehistoria. Museo Arqueológico Nacional. ruth. maicas@mecd.es la información que puede proporcionar la cerámica de cara al conocimiento de las sociedades del pasado, por las posibilidades que ofrece la Termoluminiscencia para el estudio de colecciones antiguas y por la contribución de la etnoarqueología, especialmente en relación a la cerámica (Rubio de Miguel, 1998; 2001; 2011).

\section{Trabajar con colecciones antiguas}

Como explicación a nuestro título podemos decir que muchas veces la labor del personal de un museo arqueológico (y la de los investigadores externos que estudian sus colecciones), es la de "reexcavar" en sus almacenes y archivos. Con cada nuevo proyecto se abre una larga y tediosa labor de comprobación de datos, que muchas veces proporciona un gratificante nivel de certeza, pero otras muchas desemboca en una incertidumbre aún mayor que la del comienzo.

En el caso de la colección Siret del MAN, partimos de un ingente volumen de piezas que debieron ser embaladas

\footnotetext{
Área de Prehistoria. Departamento de Geografía, Historia y Humanidades. Universidad de Almería. mproman@ual.es
} 


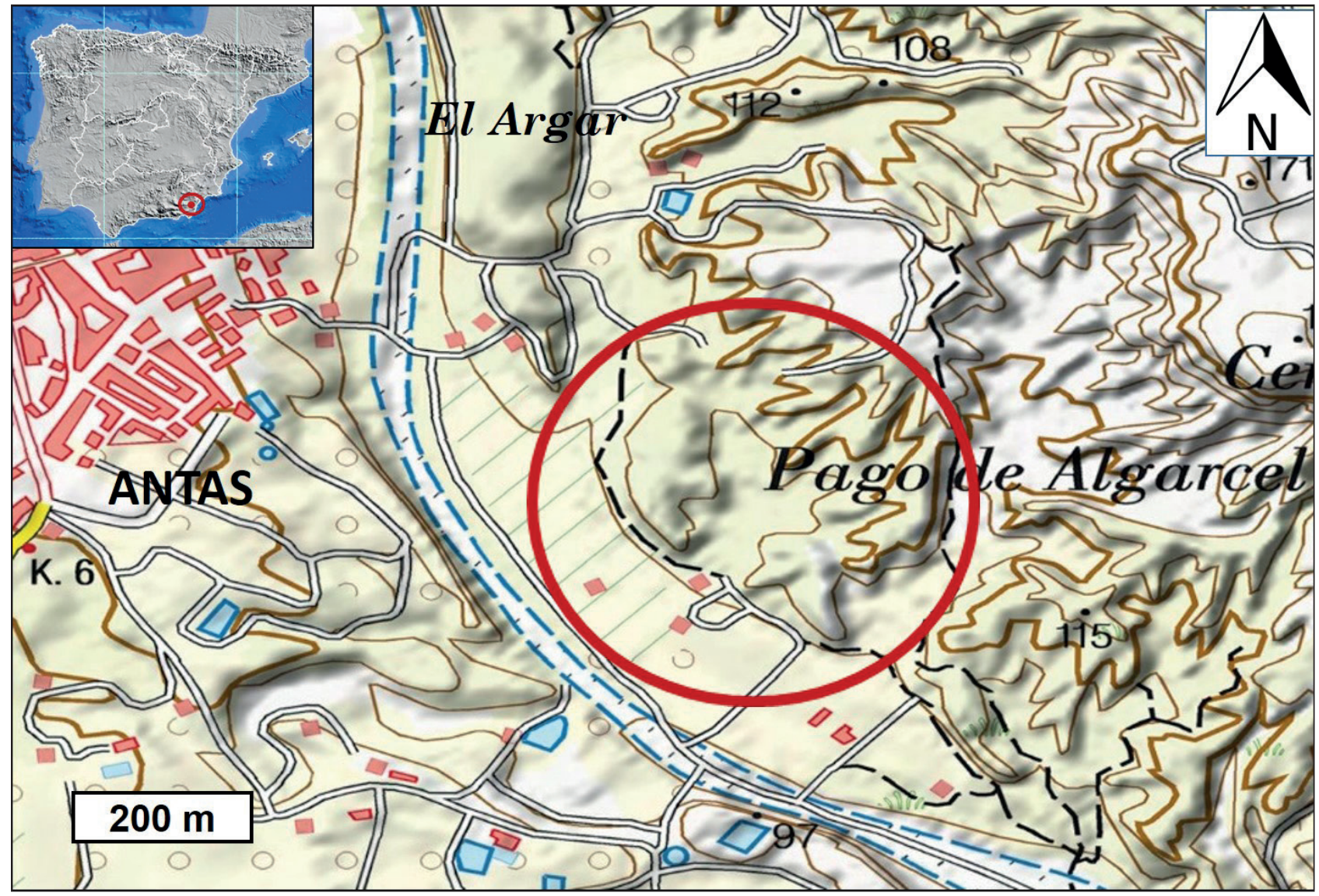

Figura 1. Mapa de ubicación. Centro Nacional de Información Geográfica. Gobierno de España, Ministerio de Fomento. Instituto Geográfico Nacional.

e instaladas por el propio autor en sus espacios de destino, pero como es bien sabido, no fue así. El proceso de empaquetado fue terminado por Joaquín María de Navascués, quien se trasladó a Almería para hacerse cargo de varios envíos. El primero estaba formado por 54 cajones y sus correspondientes 2732 kilos (MAN 1944/45/FD01076). En una carta fechada el 24 de Junio y dirigida al director del MAN, Francisco Alvarez Ossorio, Navascués relata "He echado una ojeada por las salas donde están las colecciones. Me ha dado miedo (...) Todo lo que hay son cosas menudísimas y hay cajas de ellas a centenares" (MAN Siret/FD00298). Por otro lado, su llegada a Madrid en el verano de 1935 determinaría que la apertura de las cajas no se llevase a cabo hasta casi 20 años después (Taracena del Piñal, 1953).

Pese a los problemas existentes, la ayuda del conjunto documental que custodia el MAN, nos permite reconstruir el grueso de la excavación, que como en tantas otras ocasiones, corrió a cargo de Pedro Flores, capataz de Luis Siret, y de sus hijos hasta finales de 1889, año en el que en una carta fechada en Antas el 28 de Noviembre, Flores pregunta a Siret si tapa los hoyos abiertos en El Garcel, a petición del dueño de uno de los terrenos (MAN 1944/45/FD01672). Con anterioridad a estas excavaciones, Enrique y Luis Siret sólo nos hablan de una meseta (1887).
A pesar de la visión unitaria que se tiene de este yacimiento, El Garcel ocupa en realidad dos mesetas muy próximas entre sí, de 5000 y $1200 \mathrm{~m}^{2}$. Ambas a unos 30 $\mathrm{m}$ de altura sobre el río Antas, muy cerca de otros yacimientos emblemáticos como El Argar, La Gerundia y La Pernera. Aunque Flores realizó planos de cada meseta y L. Siret se refirió a las mismas de forma independiente, finalmente estudió de forma conjunta sus materiales (Fig. 1).

Entre las dos mesetas se reparte un "campo de hoyos"3 con muy pocos indicios de estructuras de habitación y un periodo de vida muy amplio, (al menos desde finales del IV al II milenio a.C.) (Román y Maicas, 2018).

\section{UNA VISIÓN GLOBAL DEL CONJUNTO ERGOLÓGICO Y SU DOCUMENTACIÓN}

Los datos que Pedro Flores nos proporciona a través de la documentación generada en diversos formatos (cuadernos, hojas sueltas, tarjetas de visita, recortes de papel de periódico...) requieren cierta interpretación, en especial cuando no los acompaña de dibujos, ya que por senci-

A lo largo de este estudio, usaremos el término "hoyo", como ya hiciera P. Flores para referirse a las estructuras negativas. 
llos que estos sean, resultan de gran ayuda. En ocasiones habla de "flechas", "punzones", "moladeras" o "chapinetas trabajadas", que corresponden a trapecios, perforadores, molederas y glycymeris perforadas respectivamente, pero no siempre hace una referencia comprensible. Por otro lado, no en todos los casos es igual de preciso ("tres cuchillas y dos flechas", frente a "unos pedazos de perneras y guijarros"). Cuando se refiere a conjuntos grandes, tiende a ofrecer números redondos que deben interpretarse como concepto de abundancia y no como una cifra real. Para aproximarnos al contexto excavado, hemos tenido que hacer una estimación mínima de los datos de Flores cuando estos no eran numéricos, por lo que serán valores aproximados, más fiables cuanto más bajo sea el número original.

Generalmente las cifras que Flores proporciona en sus cuadernos son superiores a las piezas conservadas en el MAN. Creemos que la causa principal es que no llegó a recoger la totalidad de lo que anotaba, en especial si se trataba de objetos pesados (por ejemplo molederas) o de aquellos que consideraba de menor interés, como los restos de fauna (por ejemplo, 40 docenas de caracoles en GI $\left./ 69^{4}\right)$. No obstante, también en alguna ocasión las piezas recogidas no se guardaron correctamente y hoy se encuentran en el gran conjunto de materiales sin referencia. En líneas generales las discrepancias entre la documentación y los materiales no son significativas, aunque sí mayores en El Garcel II. En los años 50, cuando comienza la ordenación de la colección Siret, Trinidad Taracena del Piñal ya indicaba "no coinciden los objetos" y "sobra sílex" (1953). Dado que hay muy pocos materiales sin referencia a hoyo en El Garcel II, es posible que la capa superficial fuese menor.

En total, se conservan con referencia a hoyos, entre ambas mesetas, poco más de 1000 piezas (1075 números de inventario), pero sin referencia a estructura o nivel tenemos cerca de 19.000. La mayor parte de los objetos recuperados en las excavaciones correspondían a un nivel carente de estructuras ya que, según indicaban los Siret, "los vestigios prehistóricos yacían a poca profundidad, y la mayor parte hasta en la misma superficie, sin señal de construcciones, tan sólo alguna tierra carbonosa" (Siret y Siret, 1890: 6). Por lo que aquí nos incumbe, no apreciamos diferencias significativas en el reparto porcentual de materiales cerámicos entre El Garcel I y El Garcel II, pero las discrepancias observadas, creemos que se deben a diferencias metodológicas. En algunas ocasiones, Flores dejaba solos a sus hijos al frente de la excavación ${ }^{5}$, circunstancia que probablemente afectó al proceso de registro.

4 Por razones de extensión y agilidad reflejaremos la referencia mínima para su localización en el MAN. El número de inventario completo para los materiales de este hoyo 69 de El Garcel I, sería 1984/156/ GARI $/ 69 / n^{\circ}$ orden.

P. Flores comunica en una carta a L. Siret, fechada el 4 de Junio de 1889, que se va a desplazar al "Campo de Huercal" y que deja en El Garcel a parte de sus hijos "Lucas se viene conmigo y los demás quedan en el Garcel hasta que yo vuelva” (1944/45/FD01668).
Para afianzar cualquier hipótesis sería necesario conocer la estratigrafía de estas estructuras, pero en el caso de la cerámica, sabemos que algunas de ellas fueron utilizadas como recipientes en su interior e incluso reutilizadas tras una fractura que no las imposibilitaba como contenedores.

El material sin referencia es muy similar al encontrado en los hoyos, por lo que pensamos que su distribución entre las distintas estructuras debe obedecer a tareas de limpieza y colmatación posteriores al uso primario, al que como decíamos más arriba, podrían pertenecer algunas cerámicas.

Los materiales de El Garcel conservados en otros museos, no pueden ser analizados numéricamente, pero presentan características similares a los del MAN (Deramaix 1992; http://www.britishmuseum.org, http://ceres. mcu.es).

El conjunto más amplio (en torno a las 18.000 piezas) es el constituído por la piedra tallada a la que Siret otorga su mayor atención. El 86\% de los hoyos tenían sílex y/o cuarzo en su interior. Mientras que la piedra pulida se documenta en más de la mitad de las estructuras. El conjunto está formado por hachas, azuelas y cinceles que presentan una elevada fracturación (cerca de 200 fragmentos), alisadores, afiladores, machacadores, percutores y algunas molederas. Los adornos son muy escasos (fragmentos de brazalete de mármol y cinco cuentas de collar). A todo ello habría que sumar los fragmentos de colorante y los conocidos como "ídolos tipo Garcel".

El conjunto metálico es exiguo. El único objeto es un punzón calcolítico de cobre arsenicado, sin referencia a estructuras (Rovira Llorens y Gómez Ramos, 1994). A él hay que sumar fragmentos de mineral de cobre, escorias y restos adheridos a láminas de sílex (Ignacio Montero, com. pers.).

74 estructuras tienen algún elemento de industria ósea, en su mayoría de soporte malacológico. Sobre hueso y con adscripción a los hoyos, sólo conservamos 9 apuntados y un colgante sobre costilla, que es la única pieza que denota un trabajo más esmerado (Maicas Ramos, 2007: fig. III.155).

La fauna del yacimiento, supone medio centenar de restos, que en su mayoría corresponden a gasterópodos terrestres probablemente de acumulación reciente.

\section{La CERÁmica de el garcel}

\subsection{La cerámica en la colección}

Uno de los aspectos más llamativos de este yacimiento es la escasez proporcional de cerámica. Es posible que dado el estado de las piezas recuperadas (completas, grandes fragmentos, fracciones decoradas...) la recogida responda a un sesgo voluntario, pero si manejamos las cifras que proporcionan Flores y Siret, tenemos valores sólo ligeramente más altos. Los materiales excavados por Pilar Acosta (1976) presentan un panorama muy similar al conjunto estudiado en el MAN. 


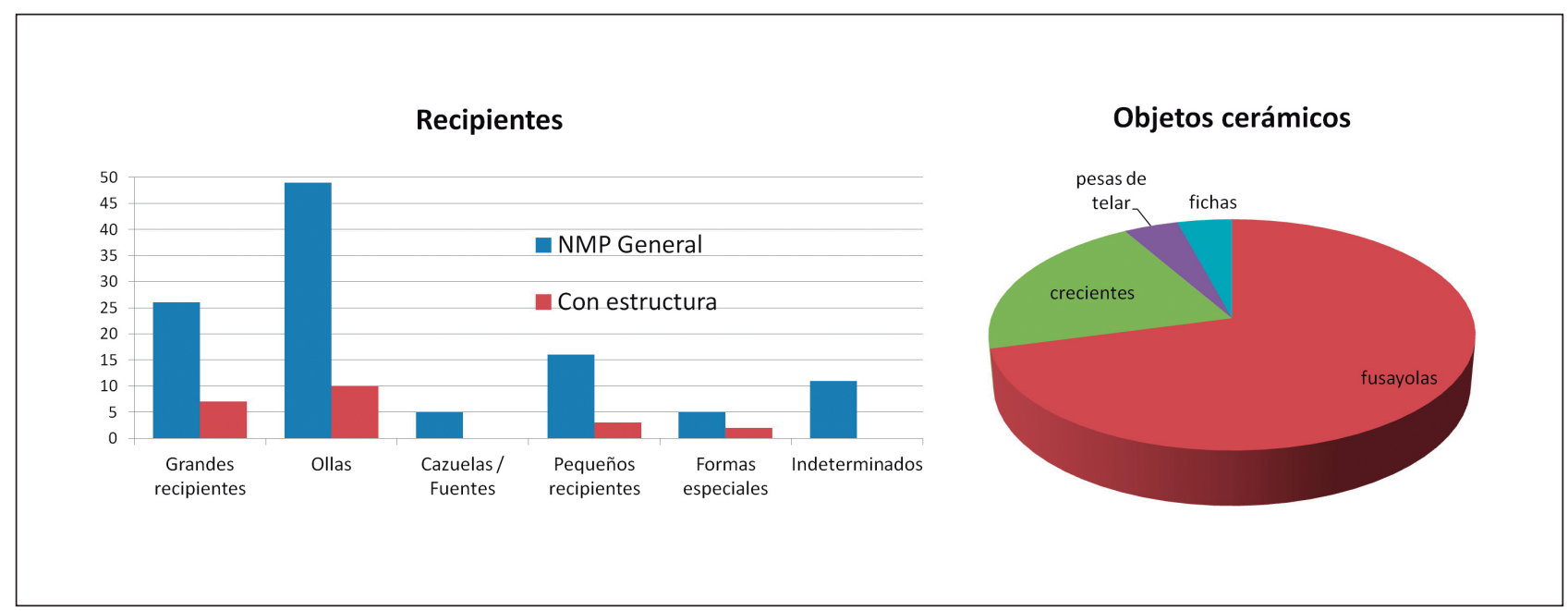

Fig. 2. Distribución general de materiales cerámicos. Estimación del NMP asignado a estructuras y del conjunto global de recipientes cerámicos de El Garcel. No se contabilizan los aproximadamente 30 fragmentos. de galbo no selectos cuyas características permiten pensar que formaban parte de los fragmentos ya contabilizados.

Es difícil conocer el número real de recipientes recuperados (Fig. 2), pero precisando la estimación de un trabajo anterior (Román y Maicas, 2018: 77) podemos decir que sólo en 50 hoyos apareció cerámica (lo que supone un $20 \%$ ), y en solo en 4 de ellos había más de dos fragmentos ${ }^{6}$.

Por lo que respecta al número de piezas (NMP), conservamos en el MAN 33 restos adscritos al conjunto de estructuras, (22 corresponden a recipientes). Siret (18912001:88) habla de unos 80 restos de cerámica, lo que no está muy alejado de nuestros cálculos (Fig. 2).

En el Archivo Siret del MAN, figuran 9 láminas de bocetos con anotaciones en las que el autor estudia los materiales cerámicos (MAN1944_45_FD01175_001r ID001 a 1944_45 FD01180_001r_ID001). Flores por su parte no muestra especial interés en ellos, dibujando sólo los de mayor tamaño o completos.

\subsection{Caracterización de las cerámicas}

Se trata en su mayoría de cerámica de color rojo-anaranjado intenso, con desgrasantes gruesos y muy gruesos ( $>5 \mathrm{~mm}$ ), entre los que dominan cuarzos y micaesquistos, con alguna presencia de caliza y ocasionalmente desgrasantes orgánicos. Las diferencias en el tamaño de grano, su bajo grado de erosión y la polimineralidad de la mayor parte del conjunto, apuntan hacia una preparación de la pasta añadiendo intencionalmente los elementos necesarios. El predominio de los esquistos parece responder a la materia prima local, sin embargo queremos resaltar que un $20 \%$ prescinde por completo de los esquistos.

6 Si nos atenemos únicamente a los datos de los materiales conservados, sólo 25 hoyos tendrían cerámica y de ellos sólo 15 tendrían recipientes.
En líneas generales estamos ante un conjunto cerámico de elaboración deficiente. A los elementos de prensión desprendidos hay que sumar los mal colocados (en diagonal respecto al eje principal) y los perforados también en diagonal, inacabados o sin eliminar las rebabas (Fig. 3). Además se observa un 7\% de piezas disgregables por mala cocción. Y por lo que respecta a los acabados, las super-

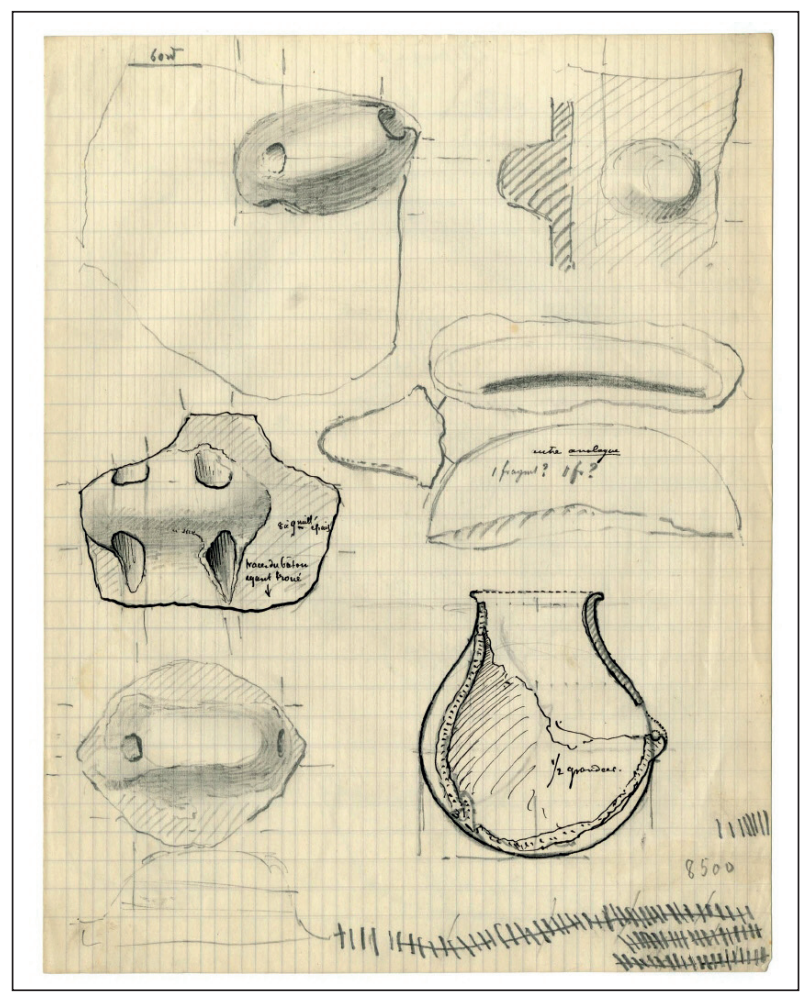

Figura 3. Olla y diversos tipos de mamelones. Los dos representados en el centro de la imagen están desprendidos del cuerpo del recipiente $y$ el del extremo superior izquierdo se colocó en diagonal respecto al borde. Dibujo de Luis Siret. Archivo del Museo Arqueológico Nacional (MAN 1944/45/FD01188_001r). 


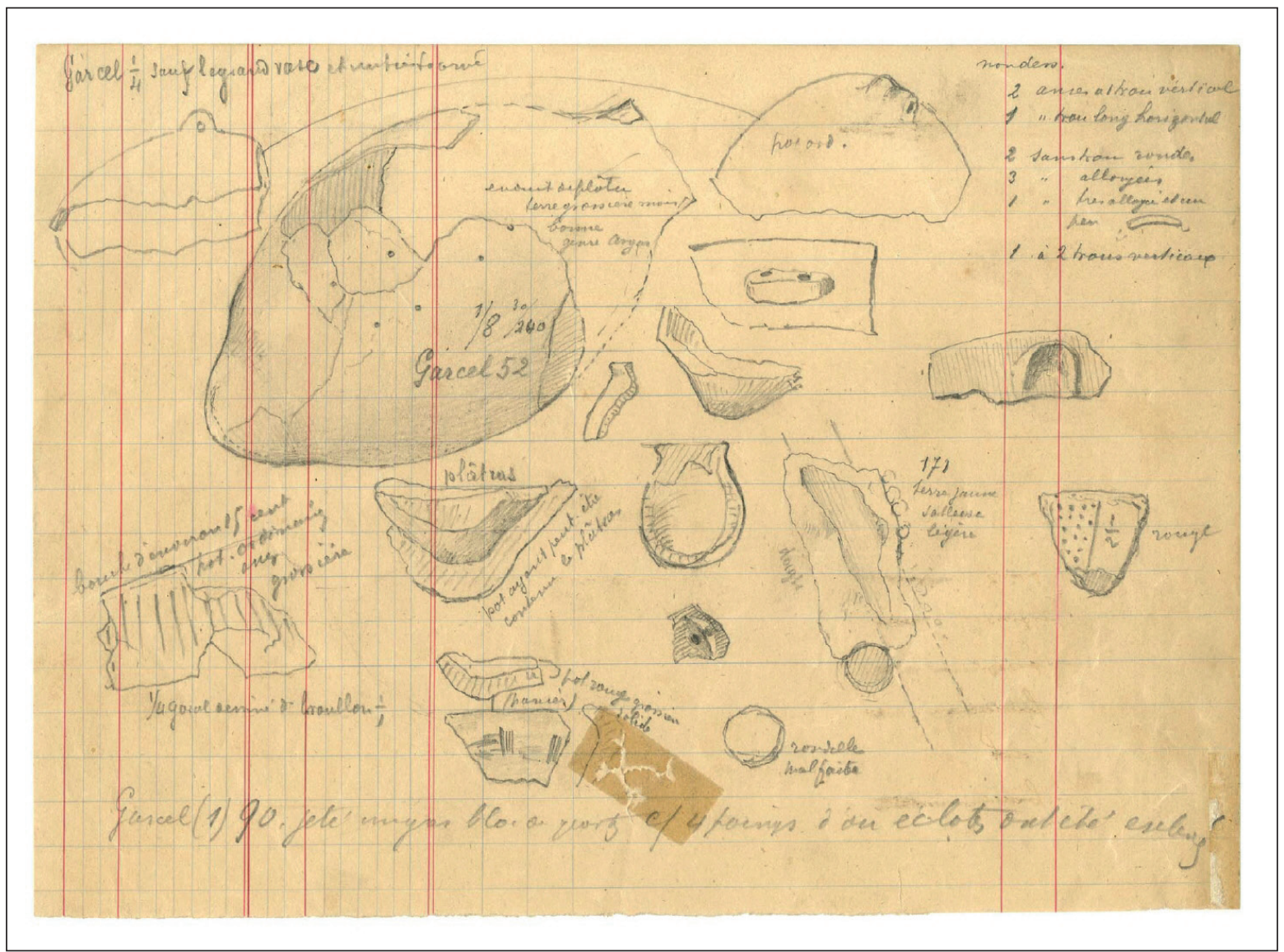

Figura 4. Selección de recipientes cerámicos. Dibujo de Luis Siret. Archivo del Museo Arqueológico Nacional (MAN 1944/45/FD01179 001r).

ficies groseras son mayoritarias, con abundantes huellas técnicas. Son pues, piezas de poca pericia o muy rápida elaboración. Siret indicó que la pasta de la cerámica era tosca, pero de cocción satisfactoria y a veces buena (Siret, 1891-2001: 86). Así mismo destacó el interés de esta sociedad por recomponer las vasijas rotas, "Las grietas fueron remendadas mediante lañas que pasan por unos agujeros" (Siret, 1891-2001: 86) (Fig. 4).

Encontramos aplicaciones irregulares de almagra y no hay apenas decoraciones exceptuando los fragmentos GAR/259, un cuello de borde engrosado con líneas incisas paralelas al eje longitudinal y GAR/263, un fragmento puntillado e inciso (Siret, 1891-2001: Lam. 31) muy similar al recuperado en un vaso carenado de Lugarico Viejo conservado en Bruselas (Cauwe, 2003: Lam. 13).

Son muy abundantes, en cambio, las asas y mamelones, necesarios para el manejo de recipientes pesados, lo que define un carácter utilitario. En este sentido hay que destacar los grandes mamelones de lengüeta (próximos a los $10 \mathrm{~cm}$ ), y las que Siret consideró "más interesantes": con forma de creciente invertido (Siret, 1891-2001: 86). En los cálculos sobre el total de piezas recuperadas hay que tener en cuenta la presencia de estos abundantes mamelones, ya que serían simétricos en las vasijas, y es muy improbable que estos grandes recipientes tuviesen menos de 2 .
En relación al grado de fracturación, del poco más de centenar de recipientes cerámicos de El Garcel, una veintena conservan más del $30 \%$ de su forma original y en su mayoría corresponden a los hoyos donde fueron depositadas, bien como elementos de almacenamiento específico (tinajas, orzas y toneles) o bien en algún caso puntual como elementos simbólicos (copa).

En el resto de los casos nos encontramos con fragmentos no necesariamente muy pequeños, pero sí proporcionalmente escasos dado el tamaño original del recipiente al que pertenecían (del 50\% de los vasos estudiados se conserva sólo el $10 \%$ o menos del recipiente original). Este segundo subconjunto de fragmentos menores y mayoritariamente desligados de un referente preciso, puede responder a los restos desechados. No detectamos fragmentos de un mismo recipiente en distintos hoyos, aunque dado el carácter de la colección es muy difícil asegurarlo.

\subsection{Grupos o conjuntos cerámicos}

Hemos distinguido tipos obedeciendo a criterios de tamaño, grosor y a relaciones de proporción y apertura, no a una identificación funcional. Así mismo se ha realizado una valoración del número real de recipientes frente 


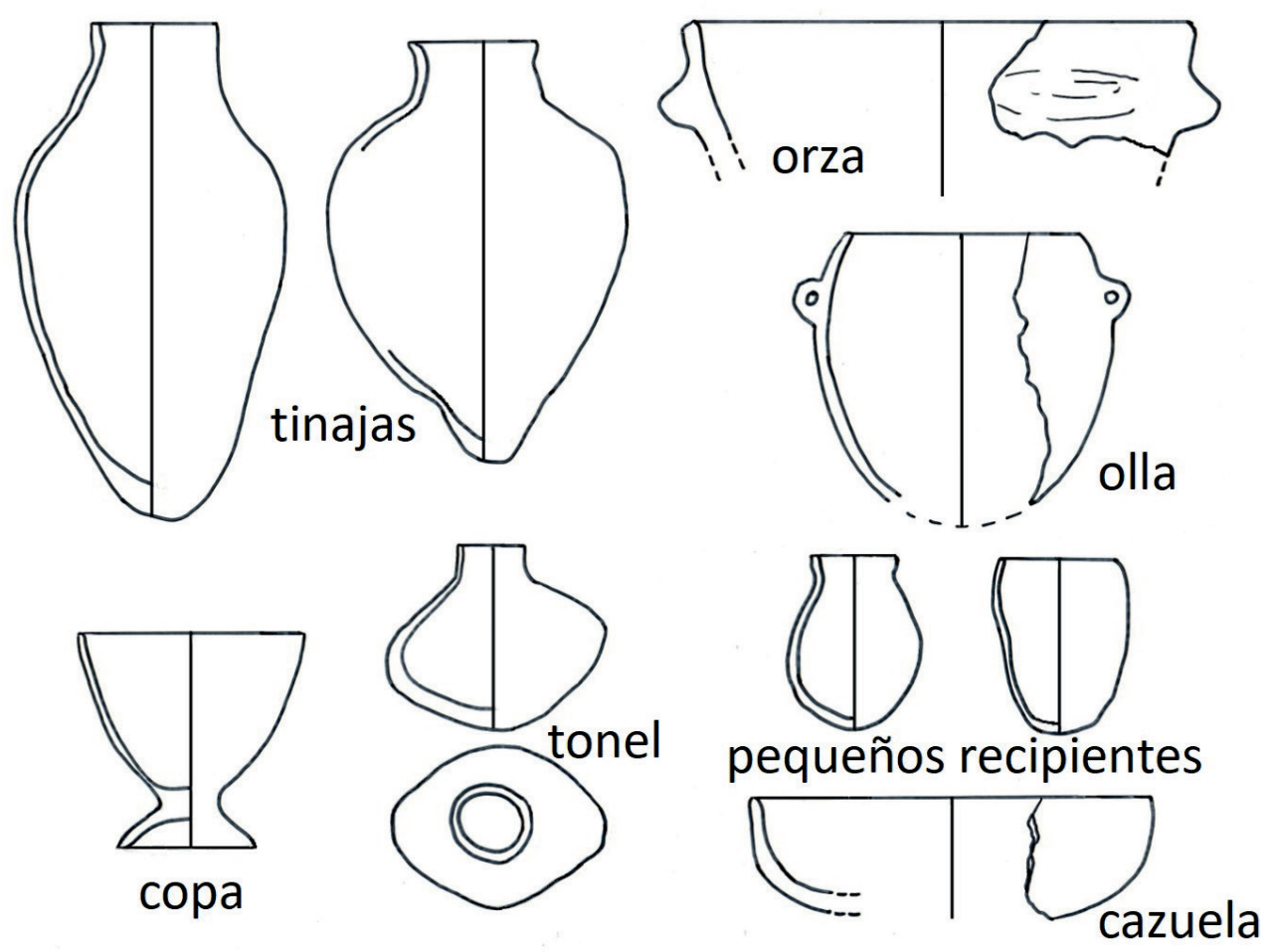

Figura 5. Tabla de formas de El Garcel. Figuras no escaladas.

al total de fragmentos, atendiendo a las características formales observadas (Fig. 5).

Por lo que respecta a una visión general de las formas identificadas, las más numerosas corresponden a tamaños medios y grandes, algo normal en las cerámicas del neolítico medio-final del sur peninsular, como corresponde a formas con un mayor uso diario y mayor fracturación (Vidal, 2008a).

Un primer bloque de recipientes de gran tamaño parte de un valor teórico de diámetro máximo superior a $30 \mathrm{~cm}$ y grosores medios por encima de $1 \mathrm{~cm}$. Dentro de este primer bloque recogemos recipientes a los que llamaremos "tinajas", por su gran capacidad y cuello marcado, y "orzas" o grandes recipientes exvasados. Un segundo bloque quedaría enmarcado entre los $15 \mathrm{~cm}$ y los $30 \mathrm{~cm}$ de diámetro. El grueso de este bloque lo constituyen las denominados genericamente "ollas" y podría corresponder tanto a recipientes de cocina como de almacenaje. Tinajas, orzas y ollas suponen un total estimado de unos 75 recipientes de gran tamaño, frente a los 34 asignados a otros tipos.

Las tinajas constituyen uno de los conjuntos más interesantes del yacimiento. Tenemos 17 de las que 6 pueden asignarse a estructuras. Son piezas de gran tamaño de formas cerradas y apuntadas que en el caso de las mejor conservadas llegaban a los $80 \mathrm{~cm}$ de altura y "debieron contener provisiones” (Siret, 1891-2001: 86).

Los fondos responden a formas cónicas generalmente muy acusadas (sólo un recipiente es claramente cóncavo (GII/28) y otros dos configuran una pequeña base plana (GI/97 y GII/37).
Los perfiles son rectos en el caso de GI/30 o sinuosos como GI/52 o GAR/266. Las calidades de los acabados son heterogéneas: alisados cuidados y desgrasantes finos en $\mathrm{GI} / 30$ o GAR/357, frente a espatulados groseros y desgrasantes muy gruesos en GII/37 o GAR/358. La alta concentración de desgrasantes en el fondo aumentaría su resistencia a impactos en los traslados.

Es particularmente interesante un fondo que conserva los restos de un revestimiento interno de yeso (1944_45 FD01179 001r-ID001) que llamó especialmente la atención de Siret (1891-2001: 87) y que relacionamos con un interés por aumentar la estanqueidad de la tinaja (Fig. 6).

Siret dibujó las formas más completas y buscó paralelos en el Norte de África, como la tinaja del yacimiento neolítico de Damous El Ahmar (Túnez) excavado por Maurice Reygasee y Marius Latapie en 1912 (Fig. 7).

Las vasijas asentadas en el fondo de los silos, como es el caso de GII/28 o GI/52, se siguieron utilizando aún fracturadas e incluso lañadas para preservar productos sólidos como olivas y uvas-pasas y separarlos de otros dentro del silo, probablemente trigo y centeno que encontraron carbonizados (Siret, 1891-2001: 85) 7 . Pero también como contenedores de elementos de un proceso de producción, como el caso de la GI/52, en cuyo interior había industria lítica.

Los macrorrestos de El Garcel corresponden a cebada desnuda (Hordeum vulgare var. nudum), centeno (Secale cereale), almortas, guijas o chicarros (Lathyrus sativus), haba panosa (Vicia faba var. minor), 


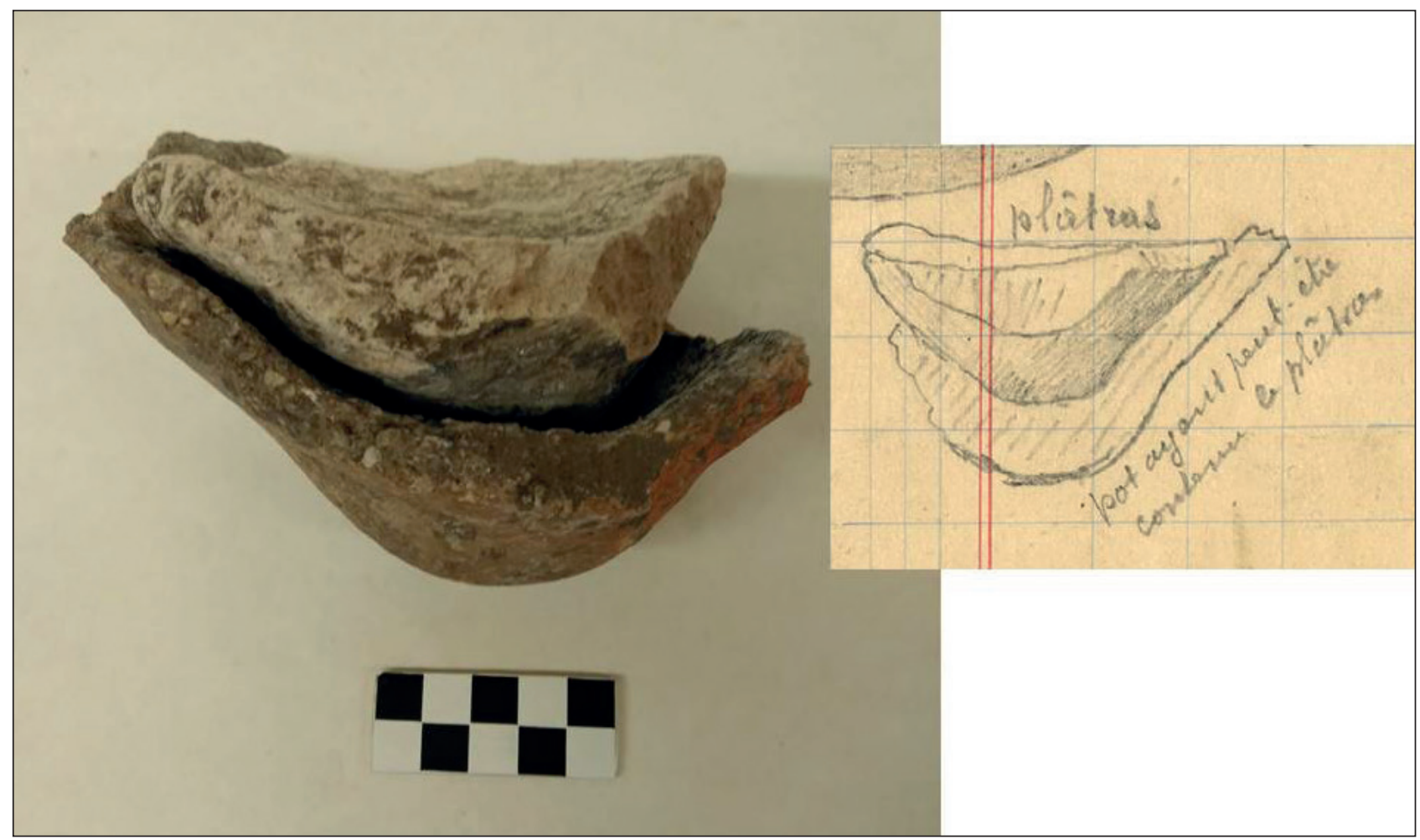

Figura 6. Tinaja con revestimiento de yeso. Dibujo de Luis Siret. Archivo del Museo Arqueológico Nacional (MAN 1944_45_FD01179_001r).

Hemos denominado "orzas" a recipientes de gran diámetro, grosor superior a $1 \mathrm{~cm}$ y grandes elementos de prensión. En los casos mejor conservados podemos apreciar formas exvasadas de borde recto, otros quedan peor definidos pero dentro de este concepto de gran formato.

Cazuelas, fuentes y ollas son recipientes de tamaño medio. Las primeras son grandes cuencos, de superficies irregularmente alisadas y desgrasantes gruesos. Las dos piezas que hemos denominado "fuentes" son 2 recipientes muy toscos, una con fuertes marcas de cesteria y otra muy alterada. Tienen diámetros de 16 y $26 \mathrm{~cm}$.

El grupo más amplio e impreciso es el formado por vasos de tamaño medio y grosores inferiores a $1 \mathrm{~cm}$ que llamamos "ollas". Es un conjunto heterogéneo que reúne, en los casos mejor conservados, tanto pequeñas orzas exvasadas con perfiles y bordes rectos, como formas invasadas, en algún caso con cuello o perfil en S. Un amplio porcentaje es imposible de asignar más allá de esta categoría de tamaño intermedio. Presentan formas esféricas, de pasta fina y compacta, adecuadas para someterse a impactos térmicos (Vidal, 2008a). También aquí son muy numerosos los elementos sustentantes (41 de los 49 asignados a este grupo).

Dentro también del grupo de tamaño medio tenemos un subconjunto que, junto a las tinajas cónicas y a la abun-

aceituna (Olea europaea) ¿olivo o acebuche?, alcaparras (Capparis sp.), uvas silvestres o lambrusca (Vitis vinifera var. sylvestris) y centeno morisco (Secale montanum) posible ancestro del centeno $(S$. cereale) (Rovira i Buendía, 2007).

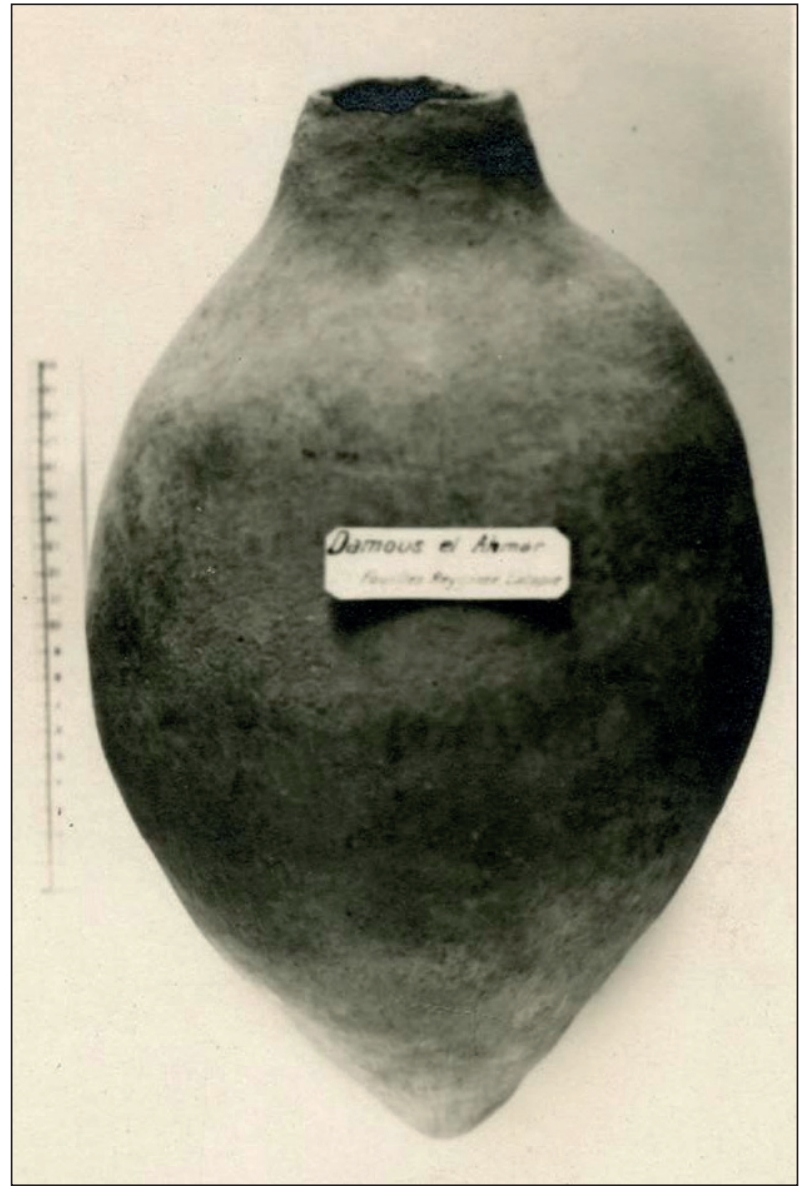

Figura 7. Tinaja del yacimiento de Damous El Ahmar. Archivo del Museo Arqueológico Nacional (MAN 1944/45/FF00156). 


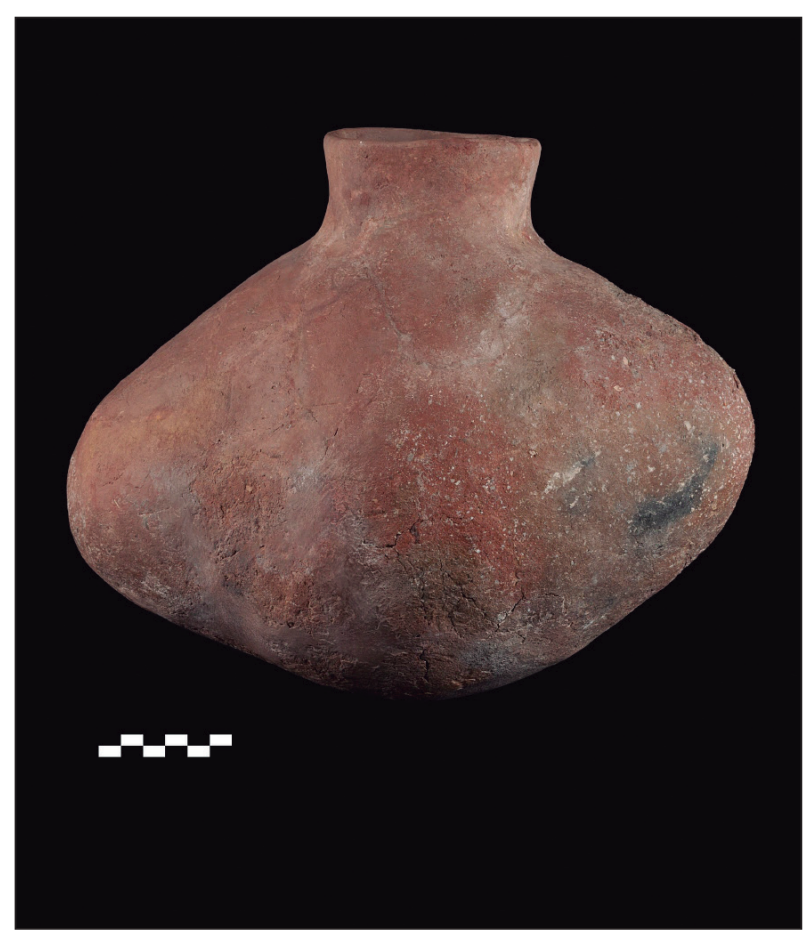

Figura 8. Tonel del hoyo 8 de El Garcel I (MAN Fotografía de Verónica Schulmeister Guillén).

dancia y variedad de elementos de prensión, caracterizan la cerámica de El Garcel, son los que en la tabla recogemos como "formas especiales": botelliformes/toneles y una copa.

Los botelliformes, son recipientes con marcada diferencia entre el diámetro de la boca y el diámetro del galbo. En el caso de El Garcel estas vasijas no corresponden a formas geométricas de revolución, sino que presentan secciones transversales elípticas o pseudorectangulares configurando una forma de tonel, sin asas. Según Siret (1891-2001: 87) hubo tres, pero a partir de los dibujos y notas de Flores, pensamos que pudieron ser incluso 4. En el MAN se conserva sólo uno, dibujado tanto por Flores como por Siret. El apunte de Flores indica su aparición en un pequeño hoyo anexo de la meseta principal (GI/8). Presenta una antigua restauración pero el $70 \%$ es original. En este caso la anchura máxima del recipiente triplica ampliamente el diámetro de la boca (Fig. 8).

Otro recipiente asignable a este tipo se encontraba en el hoyo GI/94. En esta estructura había dos vasos, pero sólo conservamos el que no responde a estas características. Además contamos con el recipiente representado en Las primeras Edades del metal (Siret y Siret, 1890: Lam. I: 63) y finalmente Flores dibuja otro botelliforme en la página 12 del cuaderno XXIV, donde documenta materiales no asignados a ninguna estructura excavados a lo largo de 1888. Pensamos que también se refiere a este último en una carta dirigida a Luis Siret. Si comparamos estos dibujos con los anteriores, en ellos se presenta un cuello muy marcado y mayor desproporción aún respecto a la medida del galbo. La carta se fecha el

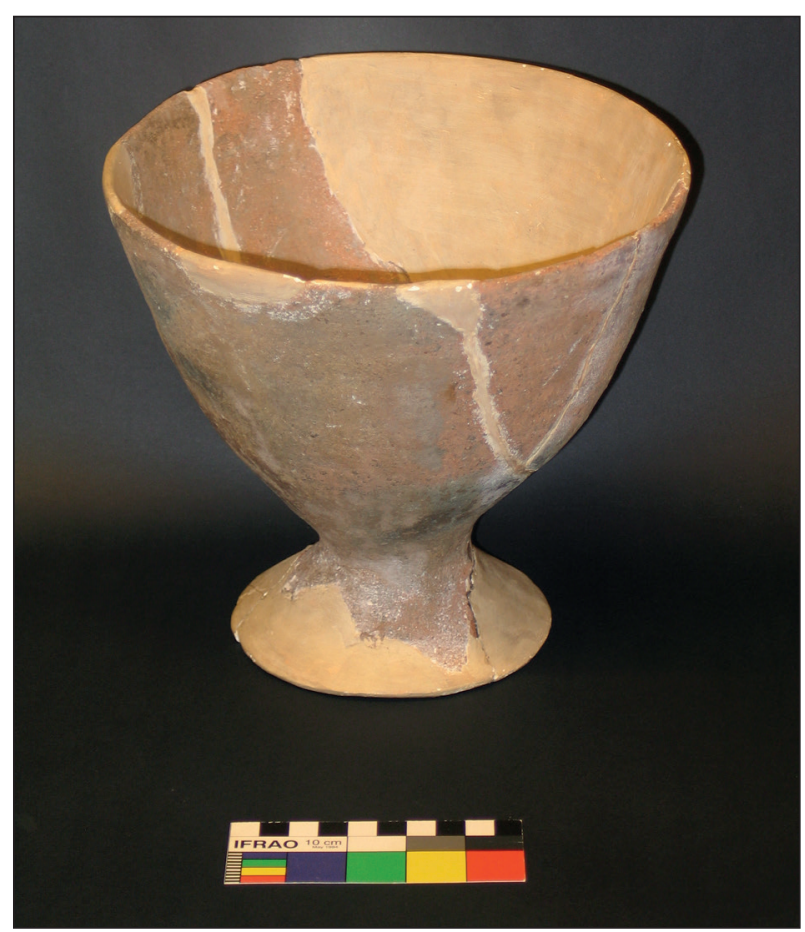

Figura 9. Copa del hoyo 146 de El Garcel.

17 de Diciembre de 1888, y Flores no excavará el hoyo 8 hasta el 11 de Febrero de 1889, por lo que tiene que tratarse de piezas distintas (MAN 1944/45/FD00844 y MAN 1944/45/FD01660).

Dentro del subgrupo de las "formas especiales" se conserva en los fondos del MAN una copa que no responde a los patrones argáricos "clásicos". Mientras las copas argáricas (ya sean altas o bajas) presentan bordes invasados, cocciones reductoras, cuerpos derivados de la esfera y tratamientos bruñidos, nuestra copa tiene un perfil troncocónico, cocción oxidante, superficies alisadas y borde exvasado (Fig. 9). Se recuperó fragmentada, pero con porción suficiente para asegurar la forma reconstruida (alrededor del 75\% del recipiente original). La pasta tiene un alto contenido en hierro y los desgrasantes son finos y medios con predominio de cuarzo y esquisto ${ }^{8}$. Por otro lado, su cronología se correspondería con una fase temprana del mundo argárico (Román y Maicas, 2018: 71). Un reciente estudio de H. Schubart señala la presencia de copas desde la fase I de Fuente Álamo. Evolucionando hacia formas esbeltas y aumentando su presencia a lo largo del registro (Schubart, 2017). El estudio se centra en los pies, no pudiendo pues asegurarse todas las variantes, pero dado que la forma "copa" es un tipo muy escaso en nuestra Prehistoria, que las fechas entran en el marco general argárico y estando tan próximo el yacimiento epónimo,

8 Su altura es de $19,5 \mathrm{~cm}$, el diámetro máximo $21,6 \mathrm{~cm}$, el diámetro del pie $12,2 \mathrm{~cm}$ y el grosor medio a $1 \mathrm{~cm}$ del borde es de $0,7 \mathrm{~cm}$. 
pudo ser un prototipo o ensayo que desembocaría en las formas argáricas más conocidas.

A este respecto y enlazando con lo que comentábamos al inicio de este texto, hemos de plantear los problemas de atribución de esta pieza. La copa está siglada y guardada como perteneciente a la estructura 146 de El Garcel I, pero esta letra no parece atribuible a Siret, ni a Flores. No podemos confirmar su desembalaje en el archivo de Trinidad Taracena, ya que si bien Garcel II está practicamente completo, Garcel I no lo está, pero aparece ya expuesta con esta procedencia en las fotografías de vitrinas de los años 50, (Vazquez de Parga MAN FD00496). Flores hablaba del pitorro que se conservaba junto a ella como "barro agujereado" y señala que además de este hay “...y unos tiestos de vasija". Dado que la pieza estaba incompleta y fracturada, bien pudo no reconocer la forma o no llamarle la atención, pero nuestra duda radica en el hecho de que Siret no la dibujara, ni mencionara siendo una forma tan llamativa.

Por lo que respecta a su función, se ha relacionado el uso de estos recipientes con el consumo de zumos de uva o granada, miel, carne e incluso como lámparas (Molina Muñoz y Rosell-Melé, 2017). En este contexto la pondríamos en relación (al igual que el cráneo recuperado en el hoyo 108) con algún componente ceremonial de amortización.

Los que hemos llamado recipientes de pequeño tamaño (dimensiones inferiores a los $15 \mathrm{~cm}$ ) son vasos cilíndricos de fondo cóncavo, ollitas y cuencos (dos de ellos con rebajes a modo de posibles vertedores).

La ollita mejor conservada (GI/70) tiene cuello destacado y podría relacionarse con el pequeño almacenaje de substancias escasas o necesarias en pequeña proporción, como la sal o el ocre.

Sólo 3 recipientes podrían considerarse cuencos. Uno de ellos presenta acabados groseros y paredes gruesas como la pasta más característica de las cerámicas de El Garcel. Frente a éste, los otros dos pequeños vasos son de casquete esférico, pastas finas, bien depuradas y acabados bruñidos. Pueden corresponder a cuencos de consumo directo y pertenecer a fases más recientes, recordemos en este sentido que la proximidad a El Argar, haría que no fuesen extrañas las "visitas".

A los recipientes mencionados, tenemos que añadir un pequeño conjunto de objetos cerámicos (24) diseminados por ambas mesetas y relacionables en su mayoría con el sector textil. En su mayoría se trata de fusayolas bitroncocónicas irregulares, aunque también las hay en corona circular. Todas ellas muy toscas (Fig. 10).

Los 5 crecientes son fragmentos secados o poco cocidos. La posible pesa de telar está muy fragmentada para asegurar su asignación. No se observan desgrasantes o son de muy pequeño tamaño, por lo que debían formar parte de la composición de la arcilla utilizada.

Este conjunto incluye una ficha de $4,3 \mathrm{~cm}$ de diámetro recortada sobre un fragmento de vasija. Estas piezas se relacionan con posibles tapaderas, elementos de juego incluso de contabilidad (Rubio, 1999).

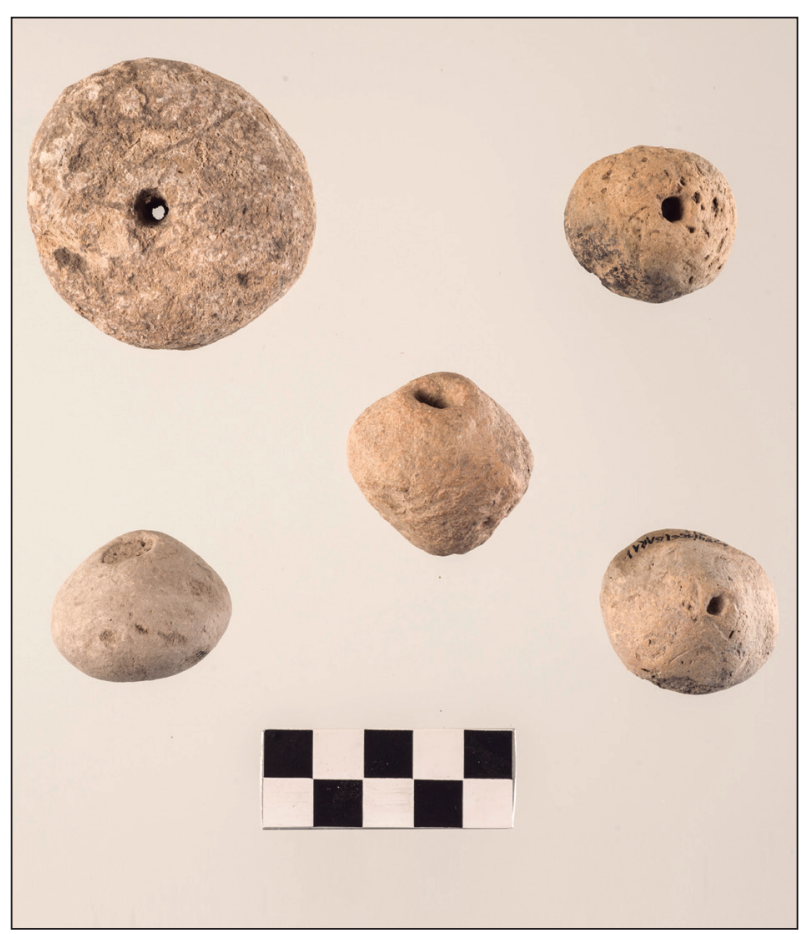

Figura 10. Fusayolas (MAN Fotografia Angel Martínez).

\section{ESTUDIO COMPARATIVO Y CONSIDERACIONES}

Dentro del mismo término municipal de Antas, otros pequeños yacimientos de la Colección Siret presentan materiales similares a los de El Garcel, como es el caso de la Loma de la Rutilla, Cabezo de Salmerón o Cabezo del Moro (Maicas y Román, 2001).

En su conjunto, los recipientes cerámicos más frecuentes en yacimientos de "silos" son domésticos, poco cuidados, con tratamiento de alisado, escasos fragmentos decorados, y formas que se reducen a botelliformes, ollas con mamelones (a veces perforados), fuentes, cazuelas y cuencos (Márquez Romero y Fernández Ruiz, 2002: 312). Si comparamos nuestros recipientes con otros conjuntos del sur peninsular en torno al IV milenio a.C., formas y posibles usos, se circunscriben a tres grandes grupos (Vidal, 2008b), en El Garcel con particularidades propias:

- Grandes recipientes, de paredes gruesas, decoración de cordones y profusión de modelos de asas. Destinadas esencialmente al almacenaje.

- Cuencos y ollas de carácter polifuncional con buen tratamiento de la superficie, escasa decoración y restos de hollín por su exposición al fuego.

- Recipientes de tamaño mediano-pequeño, abiertos y frágiles, con tratamientos cuidados, (bruñido, almagra y alguna decoración). Más propios de la esfera ritual.

En El Garcel no hay cordones y tanto la exposición al fuego como los recipientes de tratamiento esmerado son exiguos. Por otro lado, existe cierta desproporción en la distribución de nuestros recipientes dentro de estos gru- 
pos, ya que sólo documentamos bien una función frente al resto: el almacenamiento.

En el sur peninsular, las tinajas, decoradas o no, tienen una larga perduración, constatándose junto a las cerámicas decoradas típicas del "Neolítico de Cuevas" del sureste peninsular (Siret, 1891-2001: lám 32 y 33; Navarrete Enciso, 1976; Navarrete, Carrasco, Teruel y Gamiz: 1986; Eiroa, 1995: 185). Yacimientos próximos han proporcionado paralelos interesantes en lo que respecta a forma y ubicación, como es el caso de Zájara (Cuevas de Almanzora, Almería) en los estratos pertenecientes al Neolítico Reciente (Camalich Massieu y Martín Socas, 1999: 91-92) o el fondo apuntado hallado en Cabecicos Negros (Vera, Almería) junto a materiales del Neolítico Pleno, entre la segunda mitad del V milenio a.C. y el segundo tercio del IV milenio a.C. (Camalich Massieu y Martín Socas, 1999: 109 y 123).

Dos tinajas de El Garcel han proporcionado cronologías absolutas mediante TL: la recuperada en la estructura 30 de El Garcel I (GI/30), ha aportado la fecha más antigua, en torno a los 5000 años de antigüedad, y la tinaja de la estructura 52 de El Garcel I (GI/52), constituye la fecha más reciente en torno a los 3000 años de antigüedad (Román y Maicas, 2018: 71).

Por lo que respecta a los toneliformes, un pequeño recipiente (10 cm de eje mayor) sin cuello de la sepultura $1 \mathrm{de}$ Las Churuletas / Churuletes (Purchena, Almería) (Leisner y Leisner, 1943: Lam.4.2.19) parece reproducir a pequeña escala nuestros recipientes. Más próximas por tamaño y ejecución son, una pieza documentada por Juan de Vilanova y Piera en 1892 en Albox (Almería), o la expuesta en el Museo Arqueológico de Almería procedente de Los Millares (Santa Fe de Mondújar) (Ramos Lizana, 2013). Estas formas facilitan un agitado manual para elaborar mantequilla o yogourt, como se sigue haciendo hoy día en las montañas del Rif marroquí (Ramos Lizana, 2013: 136-137). En El Garcel se recuperaron completas y colocadas en el interior de los silos, lo que nos documenta otro proceso de almacenaje.

Respecto a las fusayolas de cerámica, se tiene constancia de ellas desde el Neolítico final en el arco mediterráneo occidental y desde el calcolítico inicial en la Península Ibérica (en Los Castillejos de Montefrío, Granada) hasta la Edad del Hierro (Castro Curel, 1980) tanto en contextos domésticos como funerarios campaniformes, junto a placas perforadas.

Mamelones, asas (planas, de sección anular, tubulares, mamelones perforados, etc.) y pitorros son comunes en la cerámica de la estos momentos, pero encontramos significativo su número (54 fragmentos), y la particularidad de los mamelones que dibujan una " $U$ " invertida pegada a la pared del recipiente. Siret ya señaló la existencia de uno de estos (Siret, 1891-2001: 100) en la Cueva de los Murciélagos (Albuñol, Granada), cuyas dataciones de C14 calibradas de esparto, están entre 6450-6030 a.C. y 44304000 a.C. (Cacho et al., 1996: 116, Tab. 3); en la Cueva del Toro (Antequera, Málaga) se documentó un asa similar en la subfase IIIA con dataciones de C14 no calibradas de la segunda mitad del IV milenio a.n.e (Martín, Camalich y González, 2004: 55; 112, fig. 55: 4).

\section{Cerámica y vida cotidiana. Algunas propuestas}

La arqueología y la etnoarqueología intentan aproximarnos a la cotidianidad del pasado, en el que la cerámica es un elemento clave (Rubio, 1998), ya que pastas, acabados, decoraciones, formas, tamaños y contextos de aparición nos ponen en relación con sus funciones.

En el caso de las vasijas de almacenamiento de El Garcel, sabemos que algunas aparecieron "colocadas" en el interior de hoyos que consideramos "silos" (Román y Maicas, 2018). En los sistemas tradicionales de almacenamiento, fosas y cuevas proporcionan temperaturas frescas para la conservación de alimentos, por ello en las cubetas o silos es frecuente el uso de una o varias cerámicas en el interior, que a su vez guardan otros productos (lácteos, aceite, semillas, frutas frescas, manteca de cerdo o frutos secos) cuando las fosas no están ocupadas por el grano (Miret y Mestre, 2009: 93-98). Un análisis de contenidos de nuestras vasijas afianzaría esta hipótesis.

La elaboración de la cerámica, imprescindible en la alimentación, procesado y almacenamiento de las sociedades preindustriales, es una actividad especializada ya que exige conocimientos técnicos que van desde la captación de la arcilla a la selección de los desgrasantes, pasando por la fase crítica del proceso de cocción. Los grados de dificultad varían según el tamaño y forma de la vasija que se quiera obtener. En contextos preindustriales, la repetición de formas básicas se debe a una adaptación a la función, pero también a la especialización de las alfareras (González Ruibal, 2005: 50). Las vasijas grandes, que exigen mayor pericia (elaboración del cuello o secado), suelen ser obra de una única especialista (González Urquijo et al., 2001: 13) y nadie fabrica todos los tipos de recipientes (González Urquijo et al., 2001: 51). En estos contextos la cerámica se realiza a tiempo parcial compaginando esta con otras labores (domésticas, agrícolas y ganaderas), necesarias para la subsistencia de la familia. Se requiere un proceso de aprendizaje y la producción está en manos de una o unas pocas personas de la aldea que le dedican no más de una semana de la estación seca, para su rápido secado y cocción sin riesgo de lluvias (González Urquijo et al., 2001: 9; González Ruibal, 2005: 50).

En la sociedad de El Garcel la elaboración de cerámica sería igualmente una actividad especializada y no fácil de reemplazar: su reparación mediante lañado y reciclaje así lo indican (Siret, 1891-2001: Lam. 31).

En otros yacimientos de nuestro ámbito geográfico, como es el caso de La Loma (Illora, Granada) se confirma la producción tras la recolección estival de la cosecha, a juzgar por la presencia de improntas de fibras vegetales durante su elaboración en un suelo con restos de procesado del cereal (Aranda et al., 2012: 52).

Nos preguntamos, a falta de un estudio mineralógico más especializado, si pudo llevarse a cabo en El Garcel la 
producción cerámica. A favor tenemos el hecho de poder realizar todo el proceso en una sola semana durante el verano, la ventaja que supondría elaborar "in situ" los grandes recipientes y contar con los elementos necesarios: hay molinos para triturar desgrasante y ocre, industria lítica pulida muy fracturada que se habría podido usar como mano de mortero o de molino para los desgrasantes, bastoncillos de esquisto, cantos rodados y cuchillas de sílex para el alisado, o estas últimas para regularizar la superficie o cortar el barro fresco, sencillos entramados de sombra sobre hoyos de poste para el secado de las vasijas, e incluso fosas que pudieron funcionar como horneras. Pero en contra estaría la disponibilidad de agua, más fácil junto al río.

Finalmente, las formas apuntadas de las tinajas, suelen corresponder a contenedores de líquidos, por ejemplo agua, pero esto nos lleva a otra propuesta. Una buena parte de los recipientes prenilóticos se emplean para fermentar cereal, guardar productos fermentados o para servirlos. Las vasijas fusiformes, cerradas y con fondo cónico, tienen como finalidad almacenar y fermentar la cerveza (González Ruibal, 2005). ¿Fue posible en El Garcel la fermentación del cereal para elaborar cerveza o con otros fines?. No sería algo extraño ya que en la Península Ibérica se tienen evidencias de su consumo (Can Sadurní Begues, Barcelona) desde la segunda mitad del VI milenio a.C. (Blasco, Edo y Villalba, 2008) y se multiplican posteriormente durante el período campaniforme (Guerra Doce, 2006).

\section{VALORACIÓN}

Los datos cronológicos con los que contamos nos indican un dilatado periodo de utilización del yacimiento. Posiblemente de uso temporal y recurrente, incluso cíclico pero también con hiatus.

El Garcel fue un "campo de hoyos" destinado esencialmente a un almacenamiento a media escala durante un largo período cronológico que abarcaría desde finales del IV milenio a finales del II milenio a.C. Un lugar en el que se realizaron diversas actividades económicas con exiguas evidencias de habitación (Román y Maicas, 2018). A falta de más dataciones, los conjuntos líticos y cerámicos parecen definir un primer período de ocupación más intenso y amplio que los sucesivos. La lectura de sus cerámicas parece confirmarlo, tanto por la escasez del conjunto como por sus características.

La cerámica y la industria lítica tallada se presentan como conjuntos arcaizantes, si bien la mayoría de las vasijas son de uso diario y práctico, por lo que tienden a verse menos afectadas por cambios y tendencias, por otra parte más visibles en tratamientos decorativos, muy escasos en El Garcel. No podemos dejar de insistir en el predominio lítico frente al volumen cerámico, lo que es completamente inusual en un yacimiento "Postpalelítico" en el que de un total de casi 20.000 elementos, la cerámica no llega a 150 fragmentos de recipientes y otros objetos cerámicos.

Siendo la actividad de almacenamiento la mejor con- trastada, es comprensible que la cerámica jugase un papel importante en este aspecto. Tenemos un buen número de tinajas y grandes orzas, lo que nos parece muy significativo en un conjunto tan escaso. Aunque otros recipientes de este conjunto pudieron emplearse en labores de procesado alimenticio, nos siguen pareciendo proporcionalmente escasos, lo que se suma a la pobreza de vasos para el consumo individual.

Pero este yacimiento no fue sólo un lugar relacionado con la producción, la esfera económica y la social-ritual estaban indisolublemente unidas, como apuntan el cráneo del hoyo 108 o la copa del 146, prácticas que pudieron estar relacionadas con la fertilidad de la tierra, el apoyo o protección de los antepasados (Rubio de Miguel, 2004) y/o la justificación de la apropiación comunal de ese espacio.

Todas estas propuestas tendrán una lectura más sólida con su contrastación mediante las necesarias analíticas, pero hasta entonces esperamos haber trazado algunas vías que impulsen el conocimiento de El Garcel.

\section{Agradecimientos}

Agradecemos sus comentarios y sugerencias a Aixa Vidal, Aurora Ladero, Ignacio Montero, Eduardo Galán y Katia Galán.

\section{Bibliografía}

Acosta, P. (1976): "Excavaciones en el yacimiento de El Garcel. Antas (Almería)". Noticiario Arqueológico Hispánico, 5: 189-191.

Aranda Jiménez, G.; Camalich Massieu, MªD.; Martín, D.; Morgado, A.; Martínez-Sevilla, F.; Lozano Rodríguez, J.A.; Rodríguez Rodríguez, A.; Mancilla Cabello, M $^{\mathrm{a}}$ I. y Román Punzón, J. (2012): La Loma (Íllora, Granada). Un yacimiento de fosas del VI-IV milenios cal BC. Monografías Arqueología. Junta de Andalucía. Consejería de Cultura. Sevilla.

Blasco, A.; Edo, M. y Villalba, MJ. (2008): "Evidencias de procesado y consumo de cerveza en la Cueva de Can Sadurní (Begues, Barcelona) durante la Prehistoria”. Actas del IV Congreso del Neolítico Peninsular (Alicante, 27-30 de noviembre 2006), I: 428-431.

Cacho Quesada, C.; Papi Rodes, C.; Sánchez-Barriga Fernández, A. y Alonso Mathias, F. (1996): “La cestería decorada de la Cueva de los Murciélagos (Albuñol, Granada)". Complutum Extra, 6 (1): 105-122.

Camalich Massieu, MaDD. y Martín Socas, D. (dir.) (1999): El Territorio Almeriense desde los inicios de la producción hasta fines de la Antigüedad. Un modelo: la Depresión de Vera y cuenca del Río Almanzora. Monografías Arqueología. Consejería de Cultura, Junta de Andalucía. Sevilla.

Carrasco Rus, J.V.; Teruel Berbell, Mªs.; Gámiz Jiménez, J. y Navarrete Enciso, Mas. (1986): "La Sima de los 
Intentos. Yacimiento neolítico en la costa granadina". Cuadernos de Prehistoria y Arqueología de la Universidad de Granada, 11: 27-64.

Cauwe, N. (2003): Un Âge d'Argent. Premiers agriculteurs et premiers métallurgistes dans le Sud-Est de l'Espagne. Ed. Cedarc. La collection Siret des Musées Royaux d'Art et d'Historie. Treignes (Bruxelles). Guides Archeologiques du Malgre-Tout.

Castro Curel, Z. (1980): "Fusayolas ibéricas, antecedentes y empleo". Cypsela, 3: 127-146.

Deramaix, I. (1992): La Collection Siret a Bruxelles. 1. Neolithique \& Chalcolithique. Musees Royaux d'Art et Histoire. Bruxelles.

Eiroa, J.J. (ed.) (1995): Prehistoria de la región de Murcia. Universidad de Murcia. Murcia.

González Ruibal, A. (2005): "Etnoarqueología de la cerámica en el oeste de Etiopía". Trabajos de Prehistoria, 62 (2): 41-66.

González Urquijo, J.; Ibáñez Estévez, J.J.; Zapata Peña, L. y Peña Chocarro, L. (2001): "Estudio etnoarqueológico sobre la cerámica Gzaua (Marruecos). Técnica y contexto social de un artesanado arcaico". Trabajos de Prehistoria, 58 (1): 5-27. DOI: https://doi.org/10.3989/ tp.2001.v58.i1.231

Guerra Doce, E. (2006): “Sobre la función y el significado de la cerámica campaniforme a la luz de los análisis de contenidos". Trabajos de Prehistoria, 63 (1): 69-84.

Leisner, G. y Leisner, V. (1943): Die Megalithgräber der Iberischen Halbinsel. Erster Teil: Der Süden. Römisch Germanische Forschungen 17 (Röm-German. Komm. d. Deutsch. Arch. Inst. zu Frankfurt a.m.). Berlín, Verlag von Walter de Gruyter.

Maicas Ramos, R. (2007): Industria ósea y funcionalidad: Neolítico y Calcolítico en la Cuenca de Vera (Almería). Bibliotheca Praehistorica Hispana, CSIC.

Maicas Ramos, R. y Román Díaz, MP. (2001): “Asentamientos neolíticos de la Cuenca de Vera (Almería) en la Colección Siret”. Boletín del Museo Arqueológico Nacional, 19: 1-40.

Márquez Romero, J.E. y Fernández Ruiz, J. (2002): "Viejos depósitos, nuevas interpretaciones: la estructura $n^{\circ}$ 2 del yacimiento prehistórico de los Villares de Algane (Coín, Málaga)”. Mainake, 24: 301-333.

Martín Socas, D., Camlich Massieu, Mª D. y González Quintero, P. (2004): La Cueva de El Toro (Sierra de El Torcal, Antequera-Málaga): un modelo de ocupación ganadera en el territorio andaluz entre el VI y II milenios a.n.e. Monografías Arqueología. Consejería de Cultura, Junta de Andalucía. Sevilla.

Miret i Mestre, J. (2009): Sistemes tradicionals de conservació dels aliments en fosses $i$ sitges. Un enfocament multidisciplinar. Documento accesible en www. scribd.com y en www.academia.edu (Consulta 10-102017).

Molina Muñoz, E. y Rosell-Melé, A. (2017): “Aproximación a la interpretación funcional de las copas argáricas”. En J.J. López Padilla y J. A. Soler (coord.):
Tomad y bebed. Una copa para un ritual milenario. Museo Arqueológico de Alicante.

Navarrete Enciso, Mas. (1976): La Cultura de las Cuevas con Cerámica Decorada en Andalucía Oriental. Universidad de Granada.

Ramos Lizana, M. (2013): Museo de Almería: guía oficial. Junta de Andalucía, Consejería de Educación, Cultura y Deporte. Sevilla.

Román Díaz, MaP. y Maicas Ramos, R. (2002): “'Campos de hoyos' en la desembocadura del río Almanzora (Almería): Las Palas y La Era”. Complutum, 13: 51-76.

Román Díaz, MªP. y Maicas Ramos, R. (2018): "La cosecha de El Garcel (Antas, Almería): estructuras de almacenamiento en el sureste peninsular". Trabajos de Prehistoria 75 (1): 67-84.

Rovira i Buendía, N. (2007): Agricultura y gestión de los recursos vegetales en el sureste de la Península Ibérica durante la Prehistoria Reciente. Tesis Doctoral, Universitat Pompeu Fabra. Institut Universitari d'Historia Jaume Vicens i Vives. Barcelona.

Rovira Llorens, S. y Gómez Ramos, P. (1994): "Punzones y varillas metálicas en la Prehistoria reciente española: un estudio tecnológico". Espacio, Tiempo y Forma. Serie I, Prehistoria y Arqueología, 7: 371-402.

Rubio de Miguel, I. (1998): "La Etnoarqueología: una disciplina nueva en la docencia universitaria y en la investigación españolas". Cuadernos de Prehistoria y Arqueología de la Universidad Autónoma de Madrid, 25 (1): 9-33.

Rubio de Miguel, I. (1999): "Posibles sistemas de registro y contabilidad en el Neolítico del Próximo Oriente". ISIMU: Revista sobre Oriente Próximo y Egipto en la Antigüedad, 2: 223-250.

Rubio de Miguel, I. (2001): “Aportaciones al conocimiento de la Prehistoria madrileña. Dataciones por termoluminiscencia de algunos materiales cerámicos neolíticos de la colección Bento depositados en el Museo Arqueológico de Cataluña”. SPAL, 10: 157-166. DOI: https:// doi.org/10.12795/spal.2001.i10.09

Rubio de Miguel, I. (2004): "Rituales de cráneos y enterramientos en el Neolítico precerámico del Próximo Oriente". Cuadernos de Prehistoria y Arqueología de la Universidad Autónoma de Madrid, 30: 27-46. DOI: https://doi.org/10.15366/cupauam2004.30.002

Rubio de Miguel, I. (2011): “Cerámica y simbolismo. Posibles interpretaciones de algunas cerámicas peninsulares del Neolítico Antiguo". Boletín de la Asociación Española de Amigos de la Arqueología, 46: 31-52.

Schubart, H. (2017): "La aportación de las excavaciones de Fuente Álamo". En J.J. López Padilla y J. A. Soler (coord.): Tomad y bebed. Una copa para un ritual milenario. Museo Arqueológico de Alicante.

Siret, H y Siret, L. (1887): Les premiers âges du métal dans le Sud-Est de l'Espagne. Amberes.

Siret, H y Siret, L. (1890): Las Primeras Edades del Metal en el Sudeste de España. Barcelona.

Siret, L. (1891-2001): España Prehistórica. Edición fac- 
símil y traducida. Junta de Andalucía. Arráez Editores. Almería.

Taracena del Piñal, T. (1953): "Organización de la colección Siret en el Museo Arqueológico Nacional”. Revista de Archivos, Bibliotecas y Museos, $4^{\mathrm{a}}$ época, Año VII, Tomo LIX: 327-344.

Vidal, A.S. (2008a): "Los alfareros de las cuevas: propuesta de análisis de la tecnología cerámica en el neolítico medio-final andaluz". IV Congreso del Neolítico Peninsular. Alicante 2006, 2: 320-327.

Vidal, A.S. (2008b): “Cerámica y sociedad: la producción alfarera neolítica en el sur peninsular". I Jornadas de Jóvenes en Investigación Arqueológica: Dialogando con la Cultura Material. Universidad Complutense de Madrid: 163-170.

Vilanova y Piera, J. y Rada y Delgado, J.D. (1892): Geología y Protohistoria ibéricas. Tomo I, Histo- ria de España dirigida por Cánovas del Castillo. Madrid.

\section{WeBS}

Red Digital de Colecciones de Museos en España. Ministerio de Educación, Cultura y Deporte. http://ceres. mcu.es (consulta 2-12-2015)

http://www.britishmuseum.org/research/collection online/collection_object_details.aspx?objectI$\mathrm{d}=1392322 \&$ partId=1( consulta 2-12-2015)

Centro de Descargas: Centro Nacional de Información Geográfica. Gobierno de España, Ministerio de Fomento. Instituto Geográfico Nacional. Madrid. http://centrodedescargas.cnig.es/CentroDescargas/index.jsp\# (consulta 20-12-2017) 
